Asia Pacific Journal of Contemporary Education and Communication Technology

ISBN (eBook): 9780994365682 । ISSN : 2205-6181

Year: 2018 , Volume: 4, Issue: 1

\title{
UNDERSTANDING CRITICAL REFLECTIVE THINKING THROUGH THE PRISM OF EPISTEMOLOGY
}

\author{
Andriy Kovalenko \\ Toi Ohomai Institute of Technology, Rotorua, New Zealand \\ Email: andriy.kovalenko@toiohomai.ac.nz
}

\begin{abstract}
Educational practitioners may use critical reflective thinking for different reasons. Some of them want to be more mindful about themselves (Johns, 2013), while many others hope to become more prepared for challenges coming from the ever-changing environment (Bolton, 2010). Others may use it to establish the true dialogue between the teacher and the student (Ward, 2016), and some others may consider it as a tool for improving the quality of curriculum (Lawrence-Wilkes \& Ashmore, 2014). Achievement of each of these goals relies on the pre-existing knowledge of practitioners about the phenomenon they critically reflect on. This pre-existing knowledge is essential for generating the new interpretation (i.e. knowledge) of the phenomenon of practitioners' interest.

Understanding the nature of knowledge, the process of its acquisition and its limits are referred to as epistemology (Craig, 2005). In turn, the process of knowledge acquisition or 'the development of understanding' (Phillips, 2014, p. 258) is one of the main purposes of education, while 'understanding why things are as they are' (Johns, 2013, p. 2) is the goal of reflective thinking. Considered from this perspective, the process of reflective thinking should rely on some principles of epistemology. The below discussion intends to identify epistemological foundations of critical reflective thinking.
\end{abstract}

Keywords: Critical Reflective Thinking, Epistemology, Inductive and Deductive Reasoning.

\section{Epistemological Foundations of Critical Reflective Thinking}

Johns, (2013) suggested that reflection cannot be fully understood from the epistemological perspective. Clearly, the use of certain tools of reflection (i.e. epistemological techniques) is necessary, but these tools are not used in the automatic fashion. The reflective thinker is always 'mindful' of personal background (i.e. relies on ontological techniques) in the process of reflection (Johns, 2013, p.2). This understanding of the nature of epistemology does not fully correspond to how it is interpreted by other authors. Kotzee (2013) pointed out that epistemology studies not only what knowledge is (traditional understanding of epistemology), but also tries to understand the role of the knower and how to become a good knower (social epistemology).

Goldman, (1999), one of the founding fathers of social epistemology, noticed that many authors mostly focus on how individual thinkers acquire knowledge. This individualistic epistemology' approach (Goldman, 1999, p.4) can be traced in several models of reflective thinking. For example, Borton's (1970) model of reflection is based on answering a series of questions about what happened, how what happened affected the thinker and how the thinker can use the answers on the above questions (i.e. the knowledge generated by selfreflection) for self-improvement. 'Compass' model of Seidel and Blythe (1996), Gibbs' (1988) 
'Reflective Cycle' model and Johns' (1995) model of 'Structured Reflection' also require the thinker to consider questions that may increase the chances of better self-understanding. Among these models, only Johns (1995) referred indirectly to other parties involved in the situation which the thinker reflects on.

Goldman (1999) did not question the value of self-reflection, though believed that relying solely on this type of evidence is likely to produce one-sided understanding of the phenomenon. Asking opinion of other people about the phenomenon of the thinker's interest and sharing results of reflection with these people are more likely to result in finding 'true information' (Goldman, 1999, p.3).

The concept of being 'true' is one of the founding ideas of epistemology because only the 'true belief' is knowledge (Craig, 2005, p.224). The key criterion for defining whether a belief is true is the quality of evidence supporting it. However, the high quality of evidence does not make beliefs 'true' in any situation; the new evidence may undermine beliefs that are now considered to be 'true' (Craig, 2005). There are some disciplines as, for example, quantum physics, where many 'true' beliefs are short-lived. This can be the reason why people like Goldman (1999), suggested that the goal of education should not consist in transmitting ultimate truth (that may not exist), but in teaching students how to think critically themselves. Kotzee (2013) added to this argument the idea that education is not for indoctrinating 'true' beliefs, but for teaching beliefs that are justified. Therefore, if one can draw conclusions from the evidence and justify these conclusions, so that they can be accepted by others (at least for time being) as a 'true' belief, then this person can generate knowledge.

\section{Inductive and Deductive Reasoning in Critical Reflection}

There are two major approaches to generating of 'true' knowledge (the one that relies on drawing conclusions from evidence). One can either start reasoning from one's own experience or from general premises (i.e. knowledge generated by others). The former approach is referred to as inductive, while the latter one is known as deductive reasoning (Jacquette, 2008).

Several models of reflective thinking (Johns, 2013) emphasise the role of experience. It is the starting point of reflection: one experiences something, then tries to make sense of it, and, finally, based on reflection findings, decides how to behave in the future in the similar situation. Moving from observations to the conclusion about the most appropriate behaviour corresponds to the stages of inductive reasoning. This approach appears to be the most logical, since we learn from experience; we are not born with the 'innate ideas' as Locke assumed (Harrod, 1974). David Hume took this logic to the extreme and suggested that our knowledge about what we have not experienced has no justification (Lange, 2011).

Generating inductive knowledge requires the method for arguing from particulars rather than from general premises. Harrod (1974) postulated the major principles of inductive method. Firstly, observed similarities are interpreted to develop generalisations which imply the existence of uniformity among certain phenomena. Then, the generalisations established are used to make broader assumptions about the phenomena of similar kind that is still unexamined. Finally, the probability in favour of the broader assumptions established in the second stage is used to develop further generalisations.

Harrod's (1974) model of inductive reasoning can be used for interpreting Boud, Keogh and Walker's model (1985). The first stage of the latter model occurs when one 'returns to experience' or starts thinking about what was experienced. Similar processes occur in the first stage of induction of Harrod's (1974) model: data gathered during observations are analysed through the search of patterns. Boud et al. (1985) supposed that reflection (i.e. data analysis) is not feasible without 'attending to feelings' which means using positive feelings 
while dismissing the negative ones. Boud et al. (1985) suggested that removing negative feelings is necessary for a 'rational' reflection to occur (p.26). It is not clear what the authors meant by the word 'rational' in that context. But, if 'obstructive' feelings (Boud et al., 1985, p.26) are intentionally removed, then the conclusions drawn from such reflection may become one-sided and have a questionable validity. In the final stage of Boud et al.'s (1985) model, the thinker 're-examines experience' by establishing connections between the prior knowledge (the system of beliefs, feelings and behaviour relevant to what is experienced) and new knowledge (conclusions drawn from reflection). This procedure allows the thinker to integrate the mixture of prior and new knowledge into the thinker's value system. In terms of Harrod's (1974) model of inductive reasoning, the final stage of Boud et al. (1985)can be attributed to the second induction when the findings from the first induction ('return to experience' and 'attending to feelings' in Boud et al. (1985) model) are utilised to develop generalisations about something that has not been observed/experienced yet.

Boud et al. (1985), as well as some other authors of reflective thinking theories, go beyond their original observation in the final stage of their models, when reflective thinkers are supposed to decide how to deal with the similar phenomenon in the future. These decisions are based on assumptions about what has not been experienced. This means that the reflective thinker takes risks by going beyond what was observed (Lange, 2011). Using uncertain premises to make assumptions may result in conclusions that do not always reflect reality. It does not necessarily mean that the outcome of reflective thinking cannot produce accurate predictions. However, because of the uncertain premises of inductive reasoning, the level of accuracy of the thinker's assumptions cannot be clearly assessed. Kreeft (2005) even stated that inductive reasoning (i.e. reflective thinking in this context) 'yields only probability, while deduction yields certainty' (p. 16).

According to Kreeft (2005), deductive arguments can be 'true' only if three conditions are met. Any reasoning begins with premises which must be presented by using the terms that are 'clear and unambiguous' (Kreeft, 2005, p. 26). Then, the thinker must ensure that the premises are true. Finally, the arguments that follow from the premises must be 'logically valid' (Kreeft, 2005, p. 26). Each of these prerequisites for development of 'true' arguments is reflected in the corresponding stage of deductive reasoning. The first stage requires unambiguous understanding of terms that are used for constructing of premises (Kreeft, 2005). After the terms are defined, the deductive thinker can develop judgments or reflect on how one term relates to another (Kreeft, 2005). Finally, arguments (i.e. conclusions about the nature of the phenomenon) are developed by interpreting judgements (Kreeft, 2005).

Kreeft's (2005) description of the process of deductive reasoning conforms to his statement about the certainty of deduction: terms must be clear, judgments must correspond to reality, and arguments must be logically valid. Inductive reasoning (i.e. critical reflection) begins with the observation of phenomena that may not be always presented in clear and unambiguous terms. Terms are expressed in words, the meaning of which must be unequivocal. This is where the potential challenge may come from. For example, how to define 'involvement' or 'motivation' so that it can be considered as unambiguous?

To overcome this challenge, deductive thinkers must use generally accepted definitions of terms to claim that the term is 'clear and unambiguous' (Kreeft, 2005, p. 26). They can develop their premises by using the terms borrowed from existing literature. Reflective thinkers, however, firstly try to find 'assumptions' that influence their thinking (Brookfield, 2011). Clearly, each reflective thinker may have different understanding of these assumptions which makes the terms used in the description of what is observed quite ambiguous (especially from the point of view of a deductive thinker). 
The next stage of deductive reasoning, development of 'judgements', has more similarities to what is happening in the mind of a reflective (inductive) thinker than the processes occurring at the initial stages of both types of reasoning. Although the premises of reasoning appear to have different level of certainty, both deductive and inductive thinking presume appraisal of the premises (developed either on the basis of generally accepted definitions or assumptions about the phenomenon) in terms of their relationship to other phenomena. According to Brookfield's (2011) interpretation of critical thinking, these relationships can be prescriptive, causal and paradigmatic. In the case of deductive reasoning, the thinker is more focused on identifying of causal relationships, for example, "All men are mortal, and I am a man (cause), therefore I am mortal (effect)” (Kreeft, 2009, p. 166).

Arguments are developed at the final stages of both reflective (inductive) and deductive reasoning. Deductive thinkers do it by relying on two previous stages of reasoning, (1) determining the terms (by answering what is the phenomena) and (2) describing assumed relationships between these terms (Kreeft, 2005). The point is to prove that the argument is logically valid by using valid (i.e. earlier justified) evidence. The deductive thinker may claim that the outcome of reasoning is 'true' only if the terms are clear, judgments are true and logic behind the argument is valid (Kreeft, 2005). Following this rigorous sequence of reasoning stages might be one of the reasons why Brookfield (2011) stated that critical thinking 'is not the same as being logical' (p. 35). Although the reflective (inductive) thinker does not rely on the deductive reasoning logic, it would be difficult to imagine the process of critical reflection without any logic. Most models of reflective thinking follow inductive logic, which is not sequential, but proceed in a circular or spiral-like manner. The model of Boud et al. (1985) is a good example of this logic: the elements of reflection are intertwined and 'cycle back and forth continuously' (p. 36).

The outcome of reflective process is largely based on the self-analysis of a certain phenomenon rather than on the development of the argument out of the generally accepted premises. That is why few models of critical reflective thinking refer to the use of external sources of information about the phenomenon considered. Considering findings of other reflective thinkers on the same subject can be quite beneficial, though it would require even more time and efforts for reflection.

\section{Conclusion}

Both inductive and deductive reasoning can be a part of teaching practice. Reflective (inductive) thinking is more natural to use in the daily activities. Anything out of the ordinary (e.g. a student's complaint) or anything that is too ordinary (e.g. students being late to class) triggers the start of reflection. As for deductive reasoning, it would be too cumbersome to use it for something that is a part of daily routine. Deductive reasoning requires proactive thinking about what is likely to happen in the future, frequently without having the evidence to anticipate its happening. Deductive reasoning is also more appropriate for the situations when the evidence, which is quite important to ignore, already exists. For example, it makes perfect sense to utilise deduction when designing assessments. As a rule, assessments are used to test the learner's knowledge/skill regarding a certain concept which is reflected in learning outcomes of the course. In turn, these learning outcomes are supposed to comply with, for example, the graduate profile requirements. These prerequisites are often expressed in a clear and unambiguous manner, so they may not be the subject of personal reflection, unless the educational practitioner attempts to change them. 


\section{References}

i. Bolton, G., 2010. Reflective practice: Writing and professional development.. s.l.:Sage Publications.

ii. Borton, T., 1970. Reach, touch, and teach: Student concerns and process education. s.l.:McGraw-Hill Paperbacks.

iii. Boud, D., Keogh, R. \& Walker, D., 1985. Reflection: Turning experience into Learning. s.l.:Routledge.

iv. Brookfield, S., 2011. Teaching for critical thinking: Tools and techniques to help students question their assumptions. s.l.:John Wiley \& Sons.

v. Craig, E., 2005. The shorter Routledge encyclopedia of philosophy. s.l.:Routledge.

vi. Gibbs, G., 1988. Learning by doing: A guide to teaching and learning methods.. s.l.:s.n.

vii. Goldman, A., 1999. Knowledge in a social world. Oxford: Clarendon Press.

viii. $\quad$ Harrod, R., 1974. Foundations of inductive logic.. s.l.:s.n.

ix. Jacquette, D., 2008. A companion to philosophical logic. s.l.:John Wiley \& Sons.

x. Johns, C., 1995. Framing learning through reflection within Carper's fundamental ways of knowing in nursing. Journal of Advanced Nursing, Volume 22, pp. 226-234.

xi. Johns, C., 2013. Becoming a reflective practitioner. s.l.:Wiley-Blackwell.

xii. $\quad$ Kotzee, B., 2013. Education and the Growth of Knowledge: Perspectives from Social and Virtue Epistemology. s.l.:John Wiley \& Sons..

xiii. $\quad$ Kreeft, P., 2005. Socratic logic. s.l.:St. Augustine's Press..

xiv. $\quad$ Kreeft, P., 2009. Socrates Meets Kant: The Father of Philosophy Meets His Most Influential Modern Child: a Socratic Cross-examination of Kant's Critique of Pure Reason and Grounding for the Metaphysics of Morals. s.l.:Ignatius Press.

xv. Lange, M., 2011. Hume and the problem of induction Handbook of the History of logic. s.l.:s.n.

xvi. Lawrence-Wilkes, L. \& Ashmore, L., 2014. The reflective practitioner in professional education.. s.l.:Springer.

xvii. Phillips, D., 2014. Encyclopedia of educational theory and philosophy. s.l.:Sage Publications.

xviii. Seidel, S. \& Blythe, T., 1996. Reflective practice in the classroom. Unpublished article, Project Zero/ Massachusetts Schools Network.. s.l.:s.n. 